\title{
Adoptive Neuro-Fuzzy Inference System for Traffic Noise Prediction
}

\author{
Asheesh Sharma \\ CSIR-Nat. Env.. \\ Eng. \& Res Inst \\ Nehru Marg, \\ Nagpur-440020
}

\author{
Ritesh Vijay \\ CSIR-Nat. Env. \\ Eng \& Res Inst \\ Nehru Marg, \\ Nagpur-440020
}

\author{
G. L. Bodhe \\ CSIR-Nat. Env. \\ Eng \& Res Inst \\ Nehru Marg, \\ Nagpur-440020
}

\author{
L.G. Malik \\ G H Raisoni \\ College of Eng \\ Nagpur -4400001
}

\begin{abstract}
An adaptive neuro-fuzzy inference system (ANFIS) is implemented to evaluate traffic noise under heterogeneous traffic conditions of Nagpur city, India. The major factors which affect the traffic noise are traffic flow, vehicle speed and honking. These factors are considered as input parameters to ANFIS model for traffic noise estimation. The proposed ANFIS model has implemented for traffic noise estimation at eight locations. The results have been compared and analyzed with observed noise levels and the coefficient of co-relation between observed and predicted noise level was found to be in range of 0.70 to 0.95 . The model performance has also been compared with Federal Highway Administration (FHWA), Calculation of road traffic noise (CRTN) and regression noise models and it is observed that the model performs better than conventional statistical noise model. The proposed noise model is completely generalized and problem independent so it can be easily modified to prediction traffic noise under various traffic criteria and serve as first hand tool for traffic noise assessment.
\end{abstract}

\section{General Terms}

Back propagation algorithm

\section{Keywords}

Heterogeneous traffic, adaptive neural network based fuzzy inference system, noise prediction, honking.

\section{INTRODUCTION}

Traffic is an important source and contributor of noise pollution, which directly affects the human health [1]. Noise level prediction and mapping is an important aspect in urban noise monitoring and assessment. The vehicular volume in metropolitan cities is increasing phenomenally; prediction of noise pollution is becoming an integral part of environmental impact assessment. In India, the numbers of vehicles are increasing at a rate of more than $7 \%$ yearly, creating a serious threat of noise pollution [2]. In last few years, Indian cites have experienced significant structural changes due to the rapid growth in the number of motor vehicles, expansions of road network, industrialization and urbanization. These modifications led to a change in the noise levels associated with the city [3].

The studies carried out on traffic noise pollution in growing economies are limited as compared to developed countries. The metropolitan cities in India, exhibit varying characteristics like interrupted traffic flow, heterogeneous traffic conditions, lack of lane discipline and frequent honking, making formulation of a theoretical noise prediction model difficult and complex. The empirical models like USA FHWA and UK CRTN are some of the popular noise prediction models used in India [4-6]. The other noise models are ASJ, RLS-90, and Mithra are also available for noise level prediction but limited uses of these models have been so far reported [7]. Most of the noise prediction models are developed for uninterrupted and homogeneous traffic flow; results underestimate or overestimate the noise levels under interrupted and heterogeneous traffic flow conditions. For example, the CRTN model assumed average vehicles speed $50 \mathrm{~km} / \mathrm{h}$ or more for noise level prediction, but in heterogeneous traffic condition, the average speed is limited to $20-40 \mathrm{~km} / \mathrm{h}$ [8-9]. The other important characteristics of road traffic noise in India are frequent usage of honks which have not been considered so far in these models for traffic noise prediction [10-12].

The accuracy of noise prediction depends on the consistency of input data. Traffic noise data is associated with number of uncertainties i.e. honking, vehicle speed, vehicle type etc, which leads to imprecise results [13]. The empirical models are primarily not designed to predict noise level with uncertain data and shows significant difference in measured and predicted noise levels [14]. The soft computing techniques like ANFIS and artificial neural networks (ANN) have been tested for uncertain input data for nearly two decades. Some of the recent studies suggest that ANN and ANFIS tools are more effective in complex linear and nonlinear problems like noise level prediction [15-17].

The objective of the present study is to develop traffic noise model for Nagpur city under heterogeneous and frequent honking traffic conditions using ANFIS. Nagpur is a winter capital of the state of Maharashtra, the largest city in central India and third largest city in Maharashtra after Mumbai and Pune. It has population of 2,405,421 and an annual growth rate of $11.8 \%$ for vehicles $[2,18]$.

The present paper is organized in five sections: Section II provides a brief outline of the study area. Section III reviews the field data collection for traffic noise prediction. Section IV discusses the methodology of traffic noise model development. Section V presents the comparative analysis of measured and predicted noise level. In the final section, the future scope of the model has been discussed.

\section{STUDY AREA}

The study area lies between $21^{0} 4^{\prime} 0^{\prime \prime}$ to $21^{0} 12^{\prime} 0^{\prime \prime} \mathrm{N}$ and $79^{0} 2^{\prime} 0^{\prime \prime}$ to $79^{0} 10^{\prime} 0^{\prime \prime} \mathrm{E}$ in Nagpur city, Maharashtra, India. Traffic noise was measurement at eight locations on national highway (NH-7) of the city (India) namely, After airport, Before airport, Rxstation, NEERI gate no 1, Burdi, LIC chowk, Indora and Ring road (Fig. 1). 


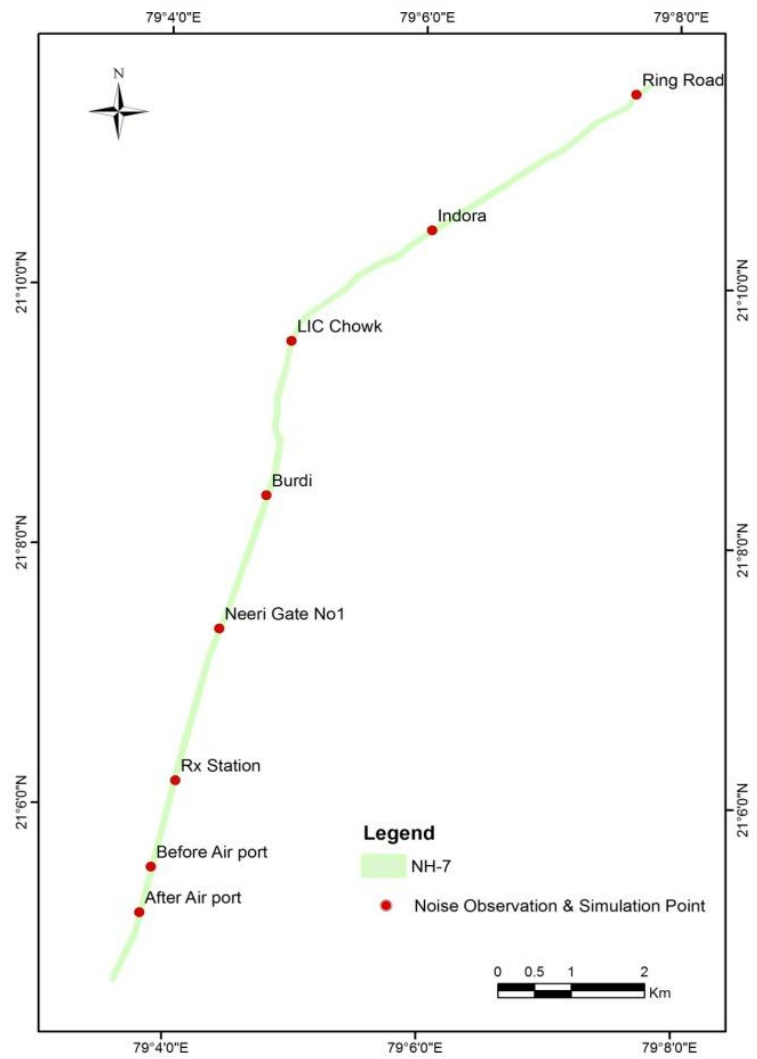

Fig. 1: Study area: National Highway-7 in Nagpur city

\section{DATA ACQUISTION}

The traffic noise, vehicle volume, vehicle composition, average vehicle speed, honking (horn counts per minute) and distant (in meters) (road centerline to sound pressure level meter) are measured at eight selected locations of Nagpur city. Traffic noise was recorded manually using sound level meter with accuracy of $\pm 0.1 \%$ [19]. Vehicle volume, average speed and honking are measured for the total duration of 15-minute with one minute intervals during morning (10:00 to $11: 00)$ and evening (18:00 to 19:00) peak traffic hours respectively at each selected location (Table 1) [5]. The vehicle volume has been classified into four categories, i.e. light vehicles (two wheelers), auto (three wheeler), medium vehicle (four wheelers), and heavy vehicles (more than four wheels). The major factors that affect traffic noise is equivalent traffic flow $\left(\mathrm{Q}_{\mathrm{E}}\right)$, equivalent traffic speed $\left(\mathrm{S}_{\mathrm{E}}\right)$ and honking. These factors are derived based on the mathematical formulation proposed by Rajakumara and Gowda shown below [20]

\subsection{Equivalent road traffic flow $\left(Q_{E}\right)$}

In this study, a composite relationship is calculated based on a factor of acoustic equivalence $E$ between the different vehicle classes. The total equivalent road traffic flow $Q_{E}$ is calculated as follows:

$$
Q_{E}=Q_{H V} * E_{H V}+Q_{\text {auto }} * E_{\text {auto }}+Q_{M V} * E_{M V}+Q_{L V}
$$

Where, $Q_{H V}, Q_{\text {auto }}, \mathrm{Q}_{\mathrm{MV}}$ and $Q_{L V}$ are total volume of heavy vehicle, auto, medium vehicles and light vehicles per minute respectively, while $E_{H V}, E_{\text {auto }}$ and $E_{M V}$ are the acoustic equivalence of heavy vehicles, auto and medium vehicles respectively. The values of $\mathrm{E}_{\mathrm{HV}}, E_{\text {auto }}$ and $E_{M V}$ are taken as $9.63,5.60$ and 2.39 respectively.

\subsection{Equivalent vehicle speed $\left(S_{E}\right)$}

Similarly, the equivalent vehicle speed $\mathrm{S}_{\mathrm{E}}$ is calculated as follows:

$\mathrm{S}_{E}=\left(\mathrm{Q}_{\mathrm{HV}} * \mathrm{E}_{\mathrm{HV}} * \mathrm{~S}_{\mathrm{HV}}+\mathrm{Q}_{\text {auto }} * \mathrm{E}_{\text {auto }} * \mathrm{~S}_{\text {Auto }}+\mathrm{Q}_{\mathrm{LV}} *\right.$

$\left.\mathrm{E}_{\mathrm{LV}} * \mathrm{~S}_{\mathrm{LV}}+\mathrm{Q}_{\mathrm{MV}} * \mathrm{~S}_{\mathrm{MV}}\right) / \mathrm{Q}_{E}$

Where, $S_{\mathrm{HV}}, \mathrm{S}_{\text {auto }}, \mathrm{S}_{\mathrm{LV}}$ and $\mathrm{S}_{\mathrm{MV}}$ are average speed of heavy vehicle, auto, light and medium vehicles respectively [5].

\subsection{Honking}

The frequent usage of honks is subtly ingrained in the driving culture of India. Some of the recent study shows that honking has significant impact on traffic noise level [10-12]. In the study, the total numbers of horns blown by different vehicles per minutes are recorded for traffic noise prediction.

\section{DEVELOPMENT OF ANFIS MODEL}

An adoptive neuro-fuzzy inference system (ANFIS) is the implementation of fuzzy inference system (FIS) to adaptive networks for developing fuzzy rules with suitable membership functions to have required inputs and outputs. It is a feedforward multi-layer Artificial Neural Network (ANN) with; partially or completely, adaptive nodes in which the outputs are predicated on the parameters of the adaptive nodes and the adjustment of parameters due to error term is specified by the learning rules. Generally learning type in adaptive ANFIS is hybrid learning [21].

In the present study, an attempt has been made to use MISO (multi inputs and single output) adaptive fuzzy model (T-S-K model) for traffic noise prediction [22-23]. ANFIS model developed in this research using MATLAB toolbox has three inputs $\left(\mathrm{Q}_{\mathrm{E}}-\mathrm{S}_{\mathrm{E}}-\right.$ Honking) and an output (equivalent traffic noise) as illustrated in Fig. 2. While developing the model 206 experimental data used. After experimenting different learning algorithms with different epochs, best correlations was found through hybrid learning algorithm and 200 epochs. In the model 3 "gbellmf" membership functions were selected for each input. The numerical ranges were used for $\mathrm{Q}_{\mathrm{E}}(45.35-$ 373.9), for $S_{\mathrm{E}}$ (23.91-49.28), for honking (1-14) respectively. Membership functions of inputs are displayed in Fig. 3a, b and c. Also the membership functions are detailed in Tables 2, 3 and 4 . Model 27 rule defines the relationship between inputs and outputs. While training the model error change is seen in Fig. 4. After training, the model was tested only using input data by defuzzification monitor. The models defuzzification monitor is shown in Fig. 5.

\section{RESULT AND DISCUSSION}

The performances of traffic noise model develop in the study has been analyzed and evaluated in this section. Fig. 6, the over-all coefficient of co-relation between observed and predicted traffic noise is found to be 0.92 . The adequacy of the developed ANFIS model was evaluated by considering the coefficient of correlation (r), standard deviation (sd) and pair2-t-test at individual sampling locations. The coefficients of correlation, standard deviation (sd) and pair2-t-test between measured and predicted noise $\left(L_{e q}\right)$ is found to be in the range of 0.70 to $0.95,1.38$ to 2.1 and 0.22 to 0.97 respectively. Best correlation is observed at 'Rxstation' with maximum honking, confirms that the model performs reasonably well under heterogeneous and frequent honking traffic conditions. The value of pair2-t-test is less than one also indicates that model can prediction traffic noise with significant accuracy. The traffic noise levels are also calculated using FHWA, CRTN and regression model [20] and results are compared with ANFIS model. The model performance and its comparison with FHWA, CRTN and regression model are given in the 
Table 3. It is observed that ANFIS model performs better than empirical noise models at each location of the study area.

\begin{tabular}{|c|c|c|c|c|c|c|c|c|c|}
\hline Locations & $\begin{array}{c}\text { Observation } \\
\text { points }\end{array}$ & Session & $\begin{array}{c}\text { Light } \\
\text { vehicles }\end{array}$ & $\begin{array}{c}\text { Medium } \\
\text { vehicles }\end{array}$ & Auto & $\begin{array}{c}\text { Heavy } \\
\text { vehicles }\end{array}$ & $\begin{array}{c}\text { Average } \\
\text { speed }\end{array}$ & Honking & distance \\
\hline \multirow{2}{*}{$\begin{array}{c}\text { After } \\
\text { airport }\end{array}$} & 1 & Morning & 351 & 236 & 10 & 124 & 49.33 & 34 & 11.54 \\
\hline & 2 & Evening & 332 & 273 & 10 & 78 & 48.80 & 24 & 11.54 \\
\hline \multirow{2}{*}{$\begin{array}{l}\text { Before } \\
\text { airport }\end{array}$} & 3 & Morning & 405 & 221 & 21 & 83 & 49.33 & 17 & 15.00 \\
\hline & 4 & Evening & 524 & 308 & 34 & 81 & 48.80 & 18 & 15.00 \\
\hline \multirow{2}{*}{ Rx station } & 5 & Morning & 703 & 345 & 48 & 108 & 42.43 & 68 & 13.16 \\
\hline & 6 & Evening & 698 & 393 & 68 & 74 & 40.83 & 80 & 13.16 \\
\hline \multirow{2}{*}{$\begin{array}{c}\text { NEERI } \\
\text { gate no. } 1\end{array}$} & 7 & Morning & 1134 & 316 & 22 & 36 & 42.43 & 63 & 12.64 \\
\hline & 8 & Evening & 1085 & 271 & 33 & 25 & 40.83 & 52 & 12.64 \\
\hline \multirow{2}{*}{ Burdi } & 9 & Morning & 615 & 90 & 221 & 18 & 26.76 & 49 & 14.41 \\
\hline & 10 & Evening & 656 & 109 & 131 & 15 & 24.42 & 42 & 14.41 \\
\hline \multirow{2}{*}{$\begin{array}{c}\text { LIC } \\
\text { chowk }\end{array}$} & 11 & Morning & 1060 & 192 & 118 & 33 & 26.47 & 79 & 5.50 \\
\hline & 12 & Evening & 914 & 211 & 72 & 16 & 27.67 & 64 & 5.50 \\
\hline \multirow{2}{*}{ Indora } & 13 & Morning & 1017 & 196 & 63 & 28 & 31.97 & 75 & 11.00 \\
\hline & 14 & Evening & 1044 & 202 & 60 & 33 & 31.97 & 39 & 11.00 \\
\hline \multirow{2}{*}{ Ring road } & 15 & Morning & 399 & 161 & 38 & 46 & 40.57 & 41 & 6.00 \\
\hline & 16 & Evening & 416 & 145 & 39 & 50 & 29.80 & 42 & 6.00 \\
\hline
\end{tabular}

Table 1. Field data for traffic noise prediction

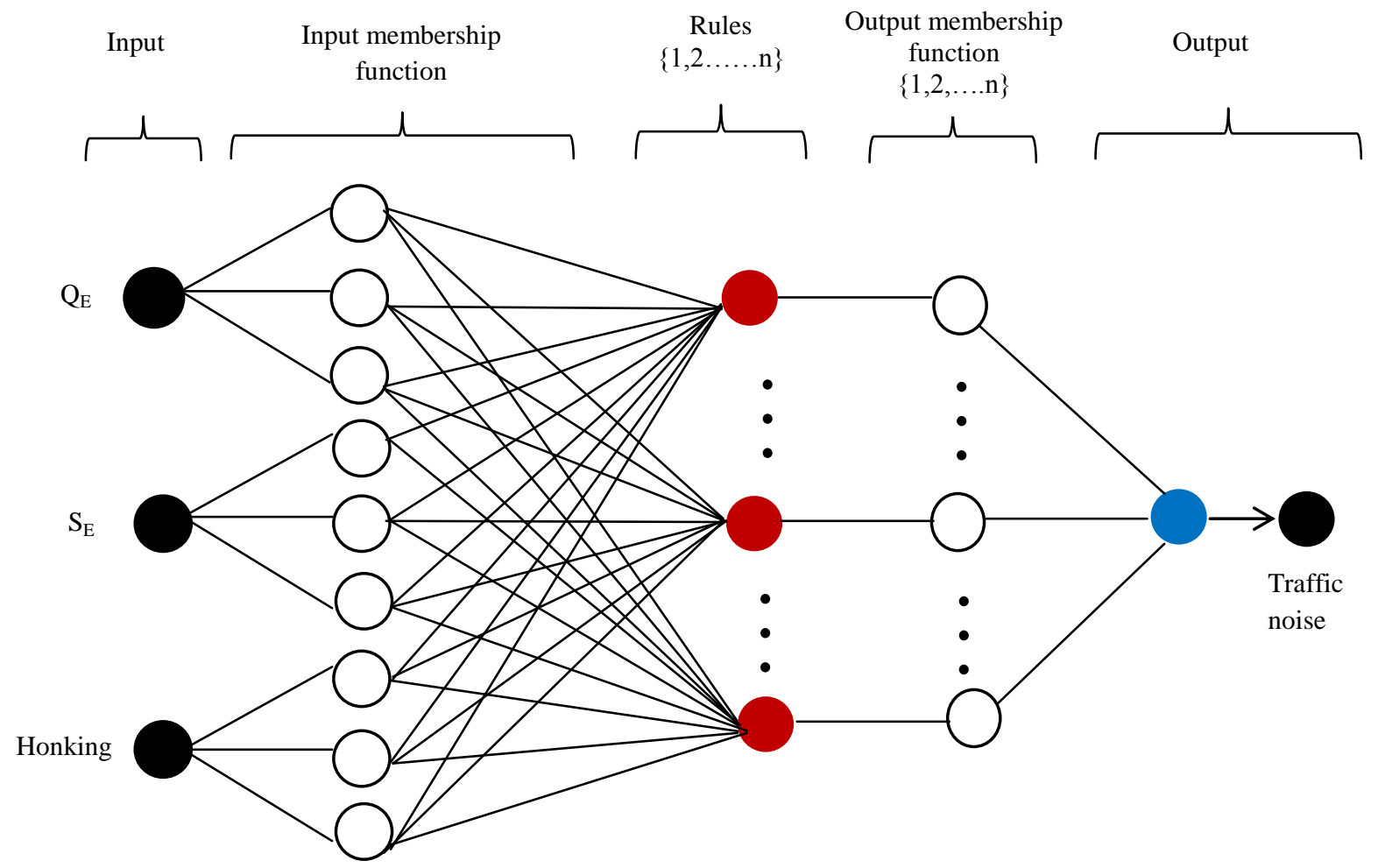

Fig. 2: Architecture of ANFIS 


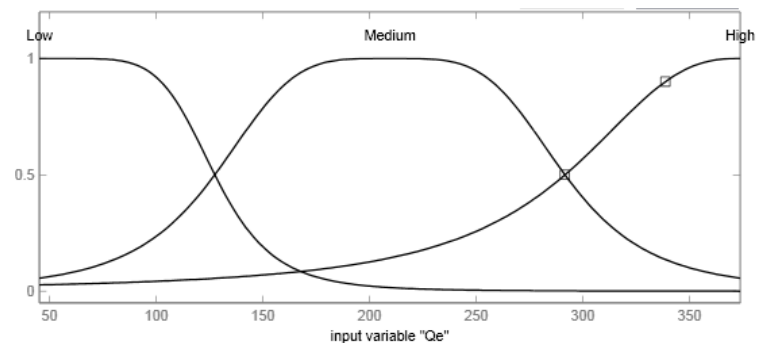

a)

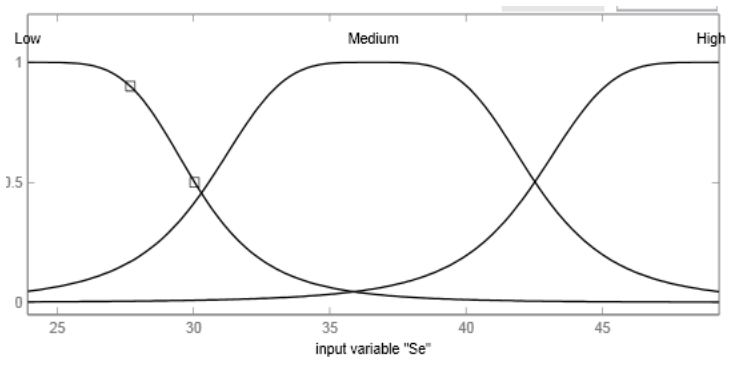

b)

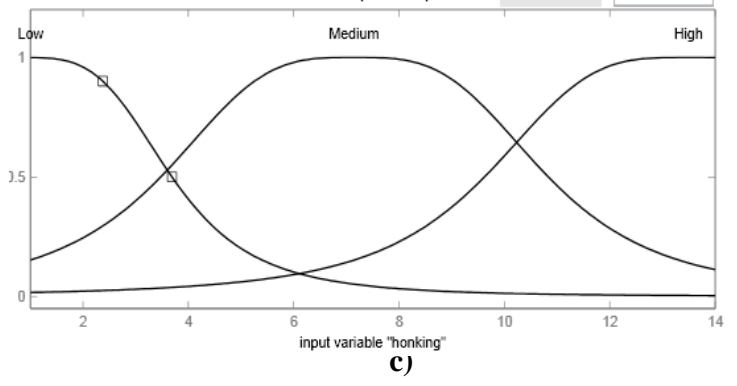

Fig. 3. Membership function a) $\left(Q_{E}\right)$, b) $\left(S_{E}\right)$, c) Honking

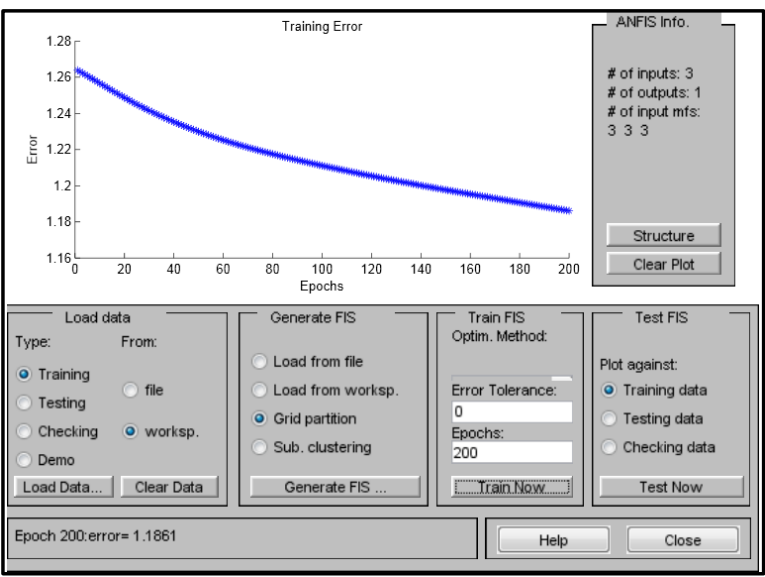

Fig. 4. ANFIS training errors
Table 2. Membership functions $\left(Q_{E}\right)$.

Input 1 Name $=' \mathrm{Q}_{\mathrm{E}}^{\prime}$

Range $=[45.35$ 373.9]

NumMFs $=3$

MF1='Low':'gbellmf', [82.19 2.99 45.43]

MF2='Medium':'gbellmf', [82.11 2.038 209.7]

MF3='High':'gbellmf', [82.17 1.293 373.9]

Table 3. Membership functions $\left(S_{E}\right)$

Input 2 Name=' $\mathrm{S}_{\mathrm{E}}$

Range $=[23.9149 .28]$

NumMFs $=3$

MF1='Low':'gbellmf', [6.193 2.295 23.85]

MF2='Medium':'gbellmf', [5.995 2.021 36.55]

MF3='High':'gbellmf', [6.538 2.177 49.05]

Table 4. Membership functions Honking

Input 3 Name='Honking'

Range $=\left[\begin{array}{ll}1 & 14\end{array}\right]$

NumMFs $=3$

MF1='Low':'gbellmf', [2.978 1.891 0.7127]

MF2='Medium':'gbellmf ', [3.679 1.666 7.154]

MF3='High':'gbellmf ', [3.885 1.741 13.51]

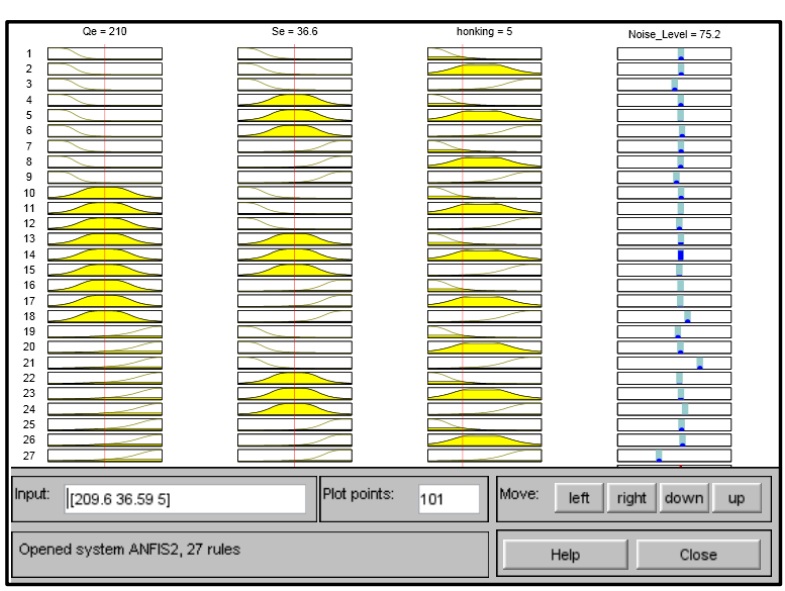

Fig 5. Defuzzification of ANFIS 
Table 5. Performance of different traffic noise prediction models

\begin{tabular}{|c|c|c|c|c|c|}
\hline Location & Performance & FHWA & CRTN & $\mathbf{R M} *$ & ANFIS \\
\hline \multirow{3}{*}{ After airport } & $\mathrm{r}$ & 0.443 & 0.384 & 0.767 & 0.910 \\
\hline & $\mathrm{sd}$ & 2.949 & 2.177 & 2.188 & 1.819 \\
\hline & pair-2 t-test & $2.0 \mathrm{E}-10$ & $6.6 \mathrm{E}-02$ & $2.0 \mathrm{E}-02$ & 4.6E-01 \\
\hline \multirow{3}{*}{ Before airport } & $\mathrm{r}$ & 0.534 & 0.509 & 0.602 & 0.702 \\
\hline & $\mathrm{sd}$ & 2.484 & 1.617 & 1.609 & 1.388 \\
\hline & pair-2 t-test & 3.4E-10 & 8.6E-02 & $6.4 \mathrm{E}-01$ & 2.2E-01 \\
\hline \multirow{3}{*}{ Rx station } & $\mathrm{r}$ & 0.770 & 0.702 & 0.734 & 0.950 \\
\hline & sd & 3.194 & 2.878 & 3.392 & 2.092 \\
\hline & pair-2 t-test & $1.8 \mathrm{E}-03$ & $7.5 \mathrm{E}-02$ & $1.3 \mathrm{E}-03$ & 6.1E-01 \\
\hline \multirow{3}{*}{ NEERI gate no.1 } & $\mathrm{r}$ & 0.471 & 0.344 & 0.825 & 0.911 \\
\hline & $\mathrm{sd}$ & 2.259 & 1.574 & 1.764 & 2.101 \\
\hline & pair-2 t-test & 4.7E-09 & $5.0 \mathrm{E}-01$ & $2.1 \mathrm{E}-02$ & 9.7E-01 \\
\hline \multirow{3}{*}{ Burdi } & $\mathrm{r}$ & 0.346 & 0.326 & 0.143 & 0.842 \\
\hline & sd & 2.397 & 1.502 & 1.680 & 1.743 \\
\hline & pair-2 t-test & $2.7 \mathrm{E}-10$ & $1.5 \mathrm{E}-02$ & $2.4 \mathrm{E}-01$ & 7.2E-01 \\
\hline \multirow{3}{*}{ LIC chowk } & $\mathrm{r}$ & 0.487 & 0.491 & 0.804 & 0.828 \\
\hline & $\mathrm{sd}$ & 1.966 & 1.627 & 1.847 & 1.648 \\
\hline & pair-2 t-test & $2.4 \mathrm{E}-03$ & $4.5 \mathrm{E}-01$ & 3.6E-01 & $9.2 \mathrm{E}-01$ \\
\hline \multirow{3}{*}{ Indora } & $r$ & 0.259 & 0.192 & 0.716 & 0.853 \\
\hline & sd & 2.072 & 1.836 & 2.048 & 2.033 \\
\hline & pair-2 t-test & $3.1 \mathrm{E}-03$ & 5.1E-01 & 4.9E-01 & 4.9E-01 \\
\hline \multirow{3}{*}{ Ring road } & $\mathrm{r}$ & 0.360 & 0.315 & 0.855 & 0.760 \\
\hline & sd & 2.361 & 2.139 & 2.380 & 1.733 \\
\hline & pair-2 t-test & $2.9 \mathrm{E}-02$ & $6.6 \mathrm{E}-01$ & 9.9E-01 & 2.4E-01 \\
\hline
\end{tabular}

*RM traffic noise model proposed by Rajakumara and Gowda [20]

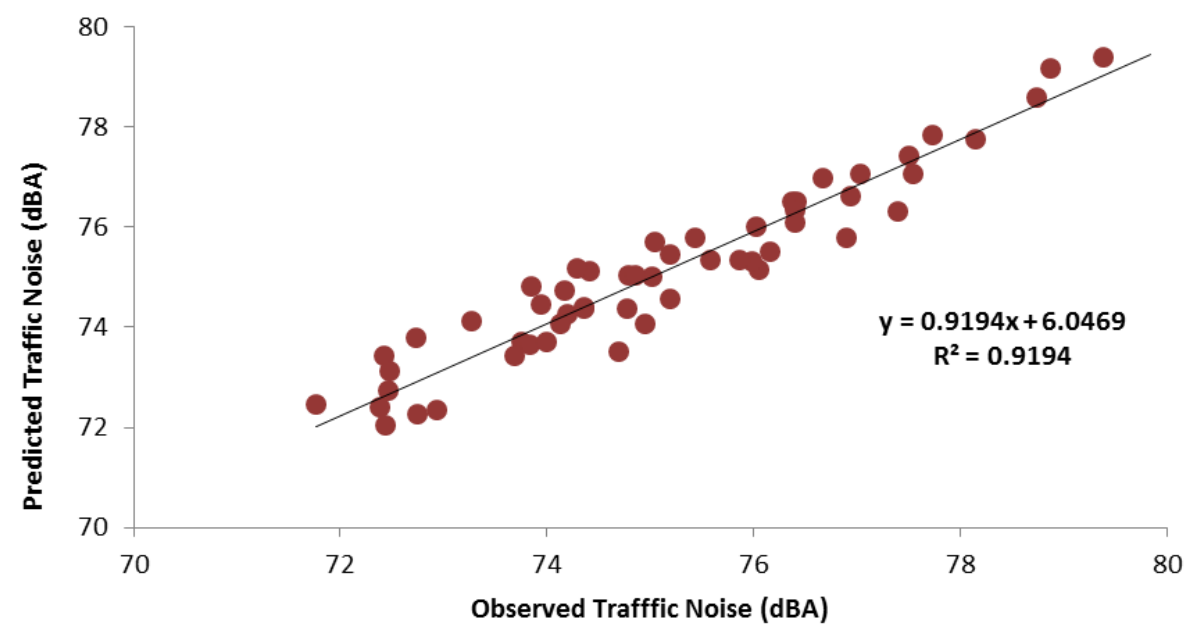

Fig. 6: Observed and predicted traffic noise 


\section{CONCLUSION}

The estimation of traffic noise under heterogeneous traffic is usually complex due to varying traffic flow, driving behavior which leads to irregular pattern of honking and other factors. At present traffic noise models are not available which considers honking as one of the parameter for traffic noise prediction. Literature reveals that honking has significant impact on traffic noise. In present study, honking has been considered for traffic noise prediction. The comparative study illustrate that model performs better than some of the popular noise models and its performance could further enhanced by incorporating honk equivalent of different vehicles for better noise pollution assessment and control.

\section{ACKNOWLEDGEMENT}

The authors are grateful to the Director, Council of Scientific and Industrial Research-National Environmental Engineering Research Institute for providing encouragement, necessary infrastructure to carry out the research, and kind permission to publish the paper

\section{REFERENCES}

[1] Banerjee, D. 2012: "Research on road traffic noise and human health in India: Review of literature from 1991 to current", Noise and Health, Vol 14, Issue 58, pp.113118.

[2] Motor transport statistics of Maharashtra 2010 - 2011. Available online on: www.mahatranscom.in/pdf/STATISTICAL.BOOK.1011.pdf

[3] Reddy, R. B., Ramachandaiah, A. 1995: "Traffice noise in some typical urban lanes", Journal of Acoustic Society of India, Vol 23, Issue 4, pp. 53-57.

[4] Mishra, R. K., Parida, M., Rangnekar S. 2010: "Evaluation and analysis of traffic noise along bus rapid transit system corridor", International Journal of Environmental Science and Technology, Vol 7, Issue 4, pp. 737-750.

[5] Sharma, A, Bodhe G. L, Schimak G. 2014: "Development of a traffic noise prediction model for an urban environment". Noise Health, Vol 16, Issue 68, pp. 63-67.

[6] Shukla, K., Jain, S. S., Parida, M., Srivastava, J. B. 2009: "Performance of FHWA model for predicting traffic noise: A case study of Metropolitan city, Lucknow (India)", Transport, Vol 24, Issue 3, pp. 234-240.

[7] Steele, C. 2012: "A critical review of some traffic noise prediction models”, Applied Acoustics, Vol 62, Issue 3, pp. 271-287.

[8] Francis, Giovanni, L. 2012: "Environmental modeling for traffic noise in urban area", American Journal of Environmental Science, Vol 8, Issue 4, pp. 345-351.

[9] Lecture 6, Objective. 1: "To learn about the standard UK method for the calculation of road traffic noise", Environmental Noise Control. Page 1/12. University of Bradford. Available online at:
www.staff.brad.ac.uk/kvhorosh/CV6505M/Lecture_06.P $D F$.

[10] Tyagi, V., Kalyanaraman, S., Krishnapuram, R. 2012: "Vehicular traffic density state estimation based on cumulative road acoustic", IEEE Transactions on Intelligent Transportation Systems, Vol 13, Issue 3, pp. 1156-1166.

[11] Wani, K. A., Jaiswal, Y. K. 2005: “Assessment of Noise Pollution in Gwalior, M.P, India", Advance in Bioresearch, Vol 1, Issue 1, pp. 54-60.

[12] Bin, J., Rui, J., Qing-Song, W., Mao-bin, H. 2005: “Honk effect in the two lane cellular automaton model for traffic flow", Physica A, Vol 348, pp. 544-552.

[13] Nanda, S. K., Tripathy, D. P., Patra, S. K. 2008: “Fuzzy inference system-based noise prediction models for opencast mines", International Journal of Mining Reclamation and Environment, Vol 23, Issue 4, pp. 242260.

[14] Kalaiselvi, R., Ramachandraiah, A. 2010: "Environmental noise mapping study for heterogeneous traffic conditions", Proceedings of $20^{\text {th }}$ International Congress on Acoustic, ICA, Sydney, Australia, pp. 2327.

[15] Nayef, M. A., Rukaibi A. F. 2012: "Neural Network Models for Traffic Noise Quality Prediction: a comparative study", Journal of Civil Environment Engineering, Vol 2, Issue 1. Available online at: http://dx.doi.org/10.4172/2165-784X.1000106

[16] Arora, J. K., Mosahari, P. V. 2012: "Artificial Neural Network Modeling of Traffic Noise in Agra-Firozabad Highway", International Journal of Computer Applications, Vol 56, Issue 2, pp. 0975-8887.

[17] Genaro, N., Torija, A., Ridao, A. R., Requena, I., Ruiz, D. P., Zamorano, M. 2010: "A neural network based model for urban noise prediction", Journal of Acoustic Society America, Vol 128, Issue 4, pp. 1738-1746.

[18] Provisional Population Totals, Census of India 2011: Available online at: http://www.censusindia.gov.in/2011provresults/paper2/data_files/India2/Table_2_PR_Cities_ 1Lakh_and_Above.pdf

[19] SoundPro, 2011: Sound Level Meter, 3M make, St. Paul, MN 55144-1000, USA.

[20] Rajakumara, H. N., Gowda, R. M. M. 2009: "Road Traffic Noise Prediction Model under Interrupted Traffic Flow Condition", Environ Modeling and Assessment, Vol 14, pp. 251-257.

[21] Jang, S. 1993: “Adaptive network-based Fuzzy Inference System”. IEEE Journal, Vol 23, Issue 3, pp. 665-685.

[22] Takagi, T., Sugeno, M. 1985: "Fuzzy identification of system and its application to modeling and control", IEEE. Trans. Syst. Man. Cyber, Vol 15, pp. 116-132.

[23] Kukolji. 2002: "Design of adoptive T-S-K fuzzy models", Appl. Soft Compt, Vol 2, pp. 89-103. 